\title{
Desain Solar Power Inverter pada Sistem Photovoltaic
}

\author{
Harmini $^{1)}$, danTitik Nurhayati ${ }^{2}$ \\ ${ }^{1,2)}$ Jurusan Teknik Elektro, Fakultas Teknik Universitas Semarang, Semarang Indonesia 50196 \\ J1. Soekarno Hatta Tlogosari, Semarang \\ Telp (024)6702757 \\ e-mail: harmini@usm.ac.id ${ }^{1)}$, ttknur@usm.ac.id $^{2)}$
}

\begin{abstract}
Solar power inverter is one of the main components in the PLTS system in order to produce the power or energy needed by the load. Solar power inverter is used to convert from DC energy (Direct Current) to AC (Alternating Current) to load. In this research a simulation of a solar power inverter system on a photovoltaic system will be designed. Simulation is done using SIMULINK-MATLAB software. Solar power inverter is designed using a boost converter as a controller and a Full-Bridge Inverter. Boost Converter is designed from 12VDC - 17 VDC to 300 VDC. Full Bridge Inverter produces AC voltage of 240 VAC with modulation index 0.8 and frequency $60 \mathrm{~Hz}$. Total Harmonic Distortion is 46.07\%. Power of Photovoltaic Solar panels generated at $3500 \mathrm{Watts}$ at $1000 \mathrm{Watt} / \mathrm{m} 2$ irradiation conditions and temperature temperatures of 25 degrees Celsius.
\end{abstract}

Keywords: Boost Converter, Inverter, Solar Power

\begin{abstract}
ABSTRAK
Solar power inverter merupakan salah satu komponen utama pada sistem PLTS agar dapat menghasilkan daya atau energi yang diperlukan oleh beban. Solar power inverter digunakan untuk mengubah dari energy listrik DC (Direct Current) menjadi energy listrik AC (Alternating Current) ke beban. Pada penelitian ini akan dirancang sebuah simulasi sistem solar power inverter pada sistem photovoltaic. Simulasi dilakukan dengan menggunakan software SIMULINK-MATLAB. Solar power inverter dirancang dengan menggunakan boost converter sebagai pengendali dan Full-Bridge Inverter. Boost Converter dirancang dari tegangan 12VDC - 17 VDC menjadi tegangan 300 VDC. Full Bridge Inverter menghasilkan tegangan AC sebesar 240 VAC dengan indek modulasi 0.8 dan frekuensi $60 \mathrm{~Hz}$. Total Harmonic Distortion sebesar $46.07 \%$. Daya panel Solar Photovoltaic yang dibangkitkan sebesar 3500 Watt pada kondisi irradiasi $1000 \mathrm{Watt} / \mathrm{m}^{2}$ dan suhu temperature sebesar 25 derajat celcius
\end{abstract}

Kata Kunci: Boost Converter, Inverter, Solar Power

\section{Pendahuluan}

$\mathrm{E}$ nergi listrik yang dihasilkan oleh sistem Photovoltaic membutuhkan sebuah sistem pengendali dan sebuah inverter yang disebut dengan solar power inverter untuk dapat menghasilkan arus listrik yang dibutuhkan oleh bebanbeban listrik rumah tangga yaitu beban listrik AC (Alternating Current). Sistem pengendali diperlukan supaya energi yang dihasilkan bisa menyesuaikan energi yang dibutuhkan beban, karena energi listrik yang dihasilkan oleh matahari selalu berubah-ubah sesuai kondisi radiasi dan temperatur sinar mahatari. Solar power inverter merupakan salah satu komponen utama pada sistem PLTS agar dapat menghasilkan daya atau energi yang diperlukan oleh beban. Solar power inverter digunakan untuk mengubah dari energy listrik DC (Direct Current) menjadi energy listrik AC (Alternating Current) ke beban[1]. Hal tersebut yang menjadikan solar power inverter dan sistem pengendali merupakan hal yang sangat penting dalam sistem PLTS. Pada penelitian ini akan dirancang sebuah simulasi sistem solar power inverter pada sistem photovoltaic. Simulasi dilakukan dengan menggunakan software SIMULINK-MATLAB. Solar power inverter yang akan dirancang memiliki fiture pure-sine dan memiliki regulasi output yang baik sesuai dengan input dari inverter. Solar power inverter dirancang menggunakan boost converter sebagai pengendali dan Full-bridge Inverter. Hasil simulasi yang dibuat nantinya akan diterapkan pada hardware yang sebenarnya. Perumusan masalah pada penelitian ini adalah bagaimana merancang dan mensimulasikan sebuah solar power inverter pada sistem Photovoltaic. Tujuan penelitian ini adalah untuk merancang dan mensimulasikan solar power inverter pada sistem photovoltaic, yang nantikan akan dijadikan acuan untuk membuat hardware yang sebenarnya.

\section{SOLAR POWER INVERTER}

\section{A. Panel Solar Photovoltaic}

Panel SPV terdiri dari beberapa sel yang terhubung secara seri untuk meningkatkan nilai tegangan yang dihasilkan dan terhubung parallel jika untuk meningkatkan nilai arus yang hasilkan. Tegangan nominal dari sistem PV harus sesuai dengan tegangan yang dibutuhkan oleh sistem penyimpanan[2]. Generator photovoltaic digunakan untuk menghasilkan daya yang dibutuhkan oleh beban, seperti ditunjukkan pada gambar 1 [2]. Panel SPV terdiri dari 2 jenis yaitu monocrystalin dan Polycrystalin. Monocrystalin dibuat 
dari silicon kristal yang besar. Panel ini sangat effisien untuk mengkonversikan sinar matahari menjadi energi listrik dengan effisiensi mencapai 18\%[3]. panel SPV monocrystalin memiliki harga yang lebih mahal dari pada polycristalin. Sedangkan panel polycristalin memiliki effisiensi sebesar $13 \%$ saampai dengan $15 \%[3]$

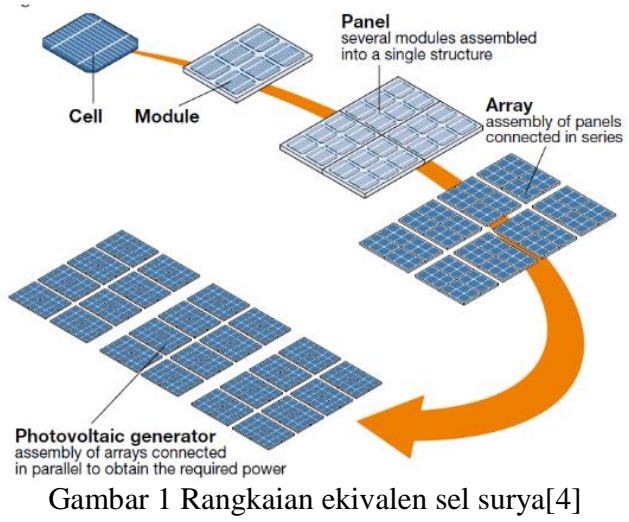

\section{B. Inverter}

Inverter digunakan untuk mengkonversi energi listrik dari baterai atau panel SPV menjadi tegangan AC yang dapat terhubung dengan jaringan PLN atau bebanbeban AC. Ada tiga jenis inverter yaitu stand alone inverter adalah inverter yang tidak terhubung dengan jaringan PLN, Grid Tie inverter adalah inverter yang dapat terhubung dengan grid PLN dan didesain secara otomatis untuk menghubungkan atau memutuskan jaringan, dan battery backup inverter adalah kombinasi dari kedua tipe inverter[6][7]. Conditioning daya dan sistem kendali dilakukan oleh inverter yang mengubah arus searah (DC-Direct Current) menjadi bolak balik (ACAlternating Current) saat ini dan kontrol kualitas output daya untuk dikirimkan ke grid, juga dengan cara filter LC dalam inverter itu sendiri[8]. Prinsip kerja inverter satu fasa ditunjukkan pada gambar 2 .skema inverter.

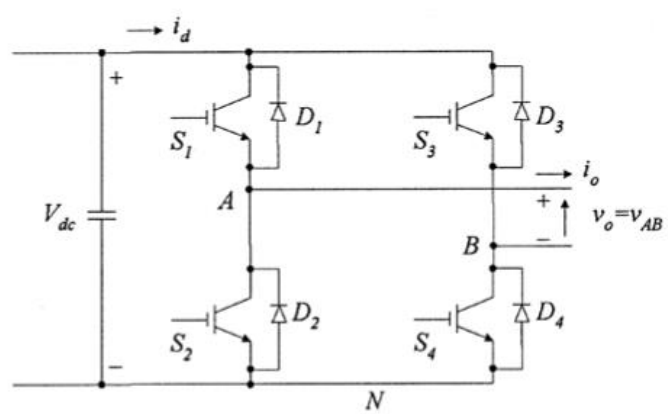

Gambar 2. Skema Prinsip Inverter Satu Fasa[8]

\section{Boost Converter}

Boost converter ditunjukkan pada Gambar 3 dapat disebut dengan step-up converter [5]. Prinsip kerja dari boost converter adalah menaikkan tegangan masukan yang rendah menjadi tegangan keluaran yang tinggi.

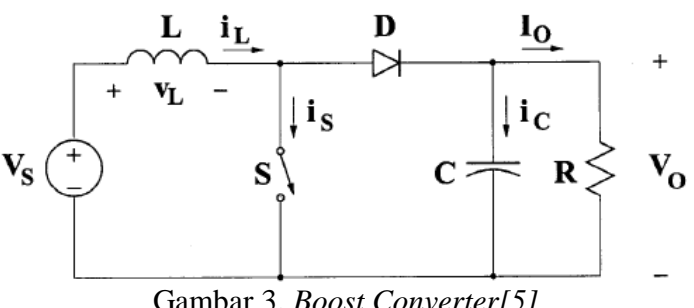

Pada saat saklar $S$ on, arus pada induktor meningkat secara linier kemudian dioda mati, sedangkan pada saat saklar $S$ off, energi disimpan didalam induktor melalui dioda kerangkaian $R$ dan $C$. Dengan menggunakan hukum Faraday didapatkan hubungan antara tegangan masukan, tegangan keluaran dan duty cycle seperti ditunjukkan pada Persamaan 1 dan 2.

$$
\begin{aligned}
& V_{i} D T=\left(V_{o}-V_{i}\right)(1-D) T \\
& \frac{V_{o}}{V_{i}}=\frac{1}{1-D}
\end{aligned}
$$

Prinsip dari CCM boost converter sebagai berikut:

1. Pada saat $t=0$ sampai $t=D$, saklar tertutup dan dioda dibias mundur (Reverse bias) yang ditunjukkan pada Gambar 4.

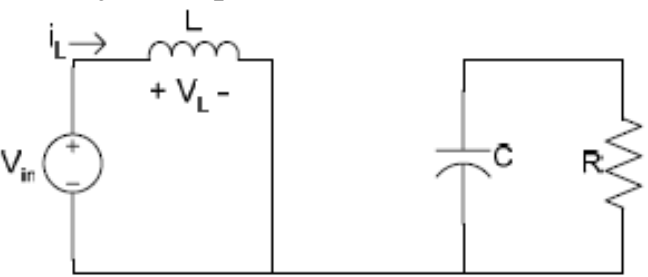

Gambar 4. Boost Converter saat saklar ditutup[5]

$$
\begin{gathered}
V_{L}=V_{i}=L \frac{d i_{l}}{d t} \\
\frac{\Delta i_{l}}{\Delta t}=\frac{\Delta i_{l}}{D T}=\frac{V_{i}}{L} \\
\left(\Delta i_{l}\right) \text { closed }=\frac{V_{\text {in }} \times D T}{L}
\end{gathered}
$$

2. Pada saat $t=(1-D) T$, dioda dibias maju (forward bias) dan saklar terbuka seperti ditunjukkan pada Gambar 5.

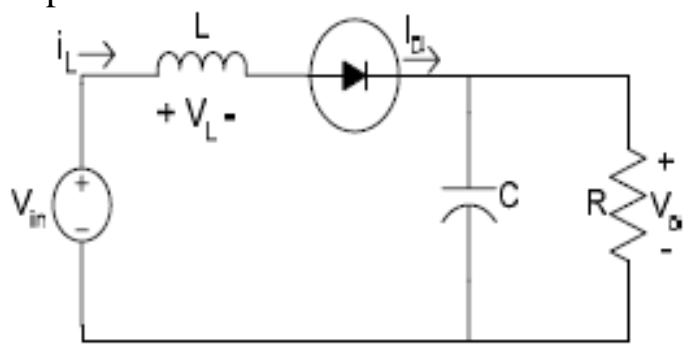

Gambar 5. Boost Converter saat saklar dibuka[5].

Tegangan dan arus induktor ditentukan berdasarkan Persamaan 4.

$$
\begin{aligned}
V_{L} & =V_{i}-V_{o}=L \frac{d i}{d t} \\
\frac{\Delta i_{L}}{d t} & =\frac{V_{i}-V_{o}}{L}
\end{aligned}
$$




$$
\begin{gathered}
\frac{\Delta i_{L}}{(1-D T)}=\frac{V_{\text {in }}-V_{o}}{L} \\
\left(\Delta i_{L}\right) \text { open }=\frac{\left(V_{\text {in }}-V_{o}\right)(1-D) T}{L}
\end{gathered}
$$

3. Untuk kondisi steady state diasumsikan bahwa arus induktor pada siklus akhir pensaklaran akan sama dengan siklus awal pensaklaran seperti ditunjukkan pada Persamaan 5

$\left(\Delta i_{L}\right)$ open $+\left(\Delta i_{L}\right)$ closed $=0$

$$
V_{i}=(1-D) V_{o}
$$

4. Untuk menentukan besarnya filter induktansi dan filter kapasitansi dengan menggunakan Persamaan 6 dan 7.

$$
\begin{aligned}
& L=\frac{(1-D)^{2} D \times R}{2 f} \\
& C_{\text {min }}=\frac{D V_{o}}{\Delta V_{o} R f}
\end{aligned}
$$

\section{METODE PENELITIAN}

Penelitian ini dilaksanakan dalam kurun waktu satu semester (6 bulan) dengan membagi dalam dua tahapan yaitu tahap persiapan, tahap kedua yaitu tahap perencanaan. Lokasi penelitian adalah di Laboratorium Konversi Energi Listrik, Teknik Elektro, Fakultas Teknik.

\section{A. Model dan Rancangan Penelitian}

Model yang digunakan dalam penelitian ini adalah perancangan dan pemodelan sistem solar power inverter pada sistem photovoltaic. Proses perencanaan berdasarkan pada skema yang ditunjukkan pada Gambar 6 dan Gambar 7.

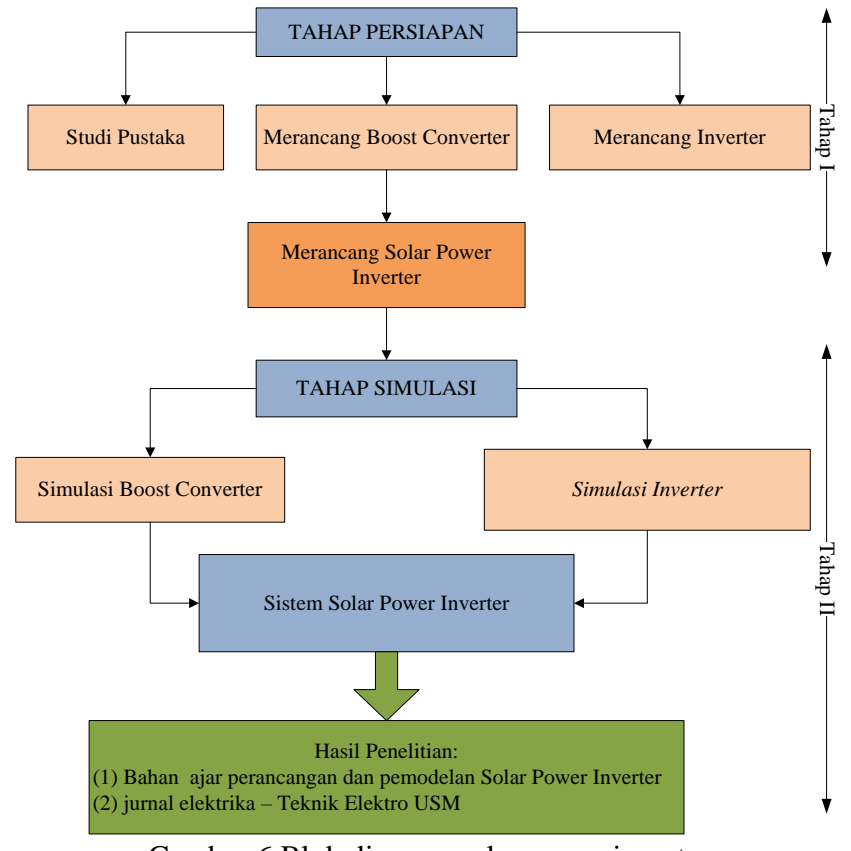

Gambar 6 Blok diagram solar power inverter
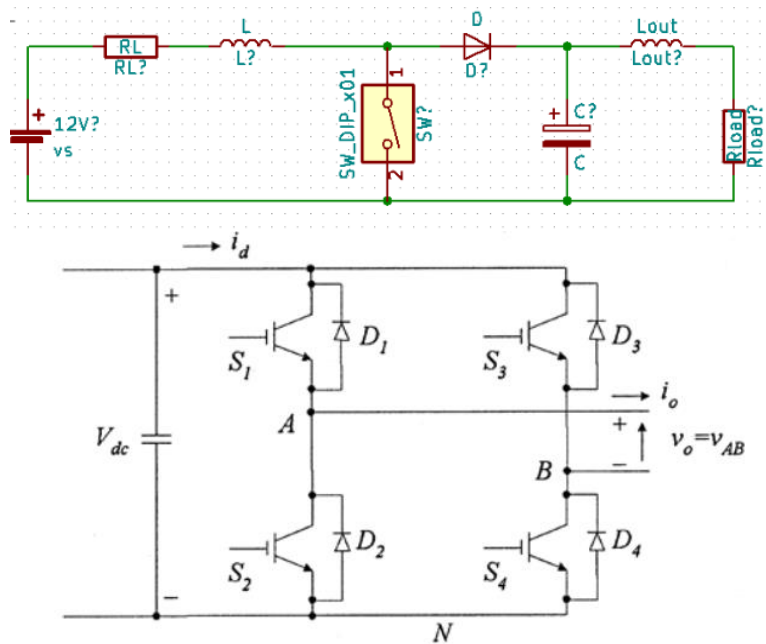

Gambar 7 Blok Diagram Solar Power Inverter

Rangkaian Full-Bridge pada penelitian ini menggunakan 4 buah IGBT atau transistor yaitu pada S1, S2, S3 dan S4 serta menggunakan dioda snubber antiparalel yang berlawanan arah pada D1, D2, D3 dan D4.

Transistor pada S1 dan S2 harus saling berkebalikan agar tidak terjadi hubung singkat, jika S1 ON maka S2 harus OFF , sehingga terjadi kombinasi pensaklaran transistor pada kondisi ON dan OFF adalah sebagai berikut:

1. S1 ON dan $\mathrm{S} 4 \mathrm{ON}$ maka beban akan dikenai tegangan keluaran $+\mathrm{Vo}$

2. S2 ON dan $\mathrm{S} 3 \mathrm{ON}$ maka beban akan dikenai tegangan keluaran $-\mathrm{Vo}_{\mathrm{O}}$

3. S1 ON dan S3 ON maka beban dikenai tegangan nol $\left(\mathrm{Vo}_{0}=0\right)$

4. S2 ON dan $\mathrm{S} 4 \mathrm{ON}$ maka beban akan dikenai tegangan nol $(\mathrm{Vo}=0)$

Kombinasi no 1 dan no 2 yang digunakan untuk mengubah tegangan DC menjadi tegangan AC. Sinyal S1, S2, S3 dan S4 dikendalikan oleh PWM dengan setting frekuensi sebesar $1080 \mathrm{~Hz}$. Parameter penting dalam pengaturan PWM adalah nilai index modulasi dan frekuensi tegangan keluaran yang digunakan untuk mengatur frekuensi tegangan keluaran AC

\section{HASIL DAN PEMBAHASAN}

Perancangan Solar Power Inverter yang terdiri dari Boost Converter dan perancangan Full-Bridge Inverter. Tegangan yang dikeluarkan oleh Solar Panel Photovoltaic sebesar $12-17$ Volt DC, tegangan ini akan dinaikkan oleh DC-DC Converter dengan topology Boost Converter sebesar 300 Volt DC, selanjutnya tegangan tersebut akan diubah menjadi tegangan $\mathrm{AC}$ sebesar 220 frekuensi $50 \mathrm{~Hz}$ sesuai dengan kebutuhan beban yang digunakan untuk peralatan rumah tangga. Secara umum blok diagram perancangan ditunjukkan pada gambar 8 . 


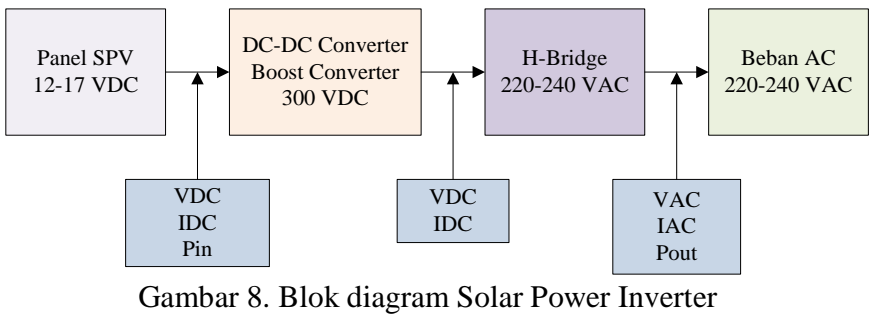

\section{A.Rangkaian Boost Converter}

Perancangan boost converter pada penelitian ini adalah tegangan input $12-17$ Volt DC hasil keluaran dari panel solar photovoltaic akan dinaikan menjadi tegangan 300 Volt DC dan arus 8A sebagai tegangan dan arus masukan pada Inverter. Frekuensi switching yang digunakan pada PWM (Pulse Width Modulation) adalah $1080 \mathrm{~Hz}$. Perancangan dan hasil keluaran rangkaian boost converter ditunjukkan pada Gambar 9 dan Gambar 10.

a. Menentukan nilai duty cycle

$$
\begin{aligned}
& \frac{V_{o}}{V_{i}}=\frac{1}{1-D} \\
& \frac{300}{12}=\frac{1}{1-D} \\
& D=1-\frac{12}{300} \\
& D=0.96
\end{aligned}
$$

b. Menghitung nilai $\mathrm{R}$

$$
\begin{aligned}
\text { Load Resistance }(R) & =\frac{V o}{I o} \\
\text { Load Resistance }(R) & =\frac{300 \mathrm{~V}}{8 \mathrm{~A}} \\
\text { Load Resistance }(R) & =37,5 \mathrm{Ohm}
\end{aligned}
$$

c. Menghitung nilai Induktor

$$
\begin{aligned}
L & =\frac{(1-D)^{2} D \times R}{2 f} \\
L & =\frac{(1-0,96)^{2} 0,96 \times 37,5}{2 \times 1080} \\
L & =26 \text { mikroHenry }
\end{aligned}
$$

Nilai induktor yang terpasang pada rangkaian adalah 1,25 kali lebih besar dari nilai perhitungan, sehingga nilai induktor adalah 1,25 x 26 mikroHenry yaitu 32,5 mikroHenry.

d. Menghitung nilai Capasitor

$$
\begin{aligned}
C_{\text {min }} & =\frac{D V_{o}}{\Delta V_{o} R f} \\
C_{\text {min }} & =\frac{0,96 \times 300}{0,001 \times 37,5 \times 1080} \\
C_{\text {min }} & =0,071 \text { Farad }
\end{aligned}
$$

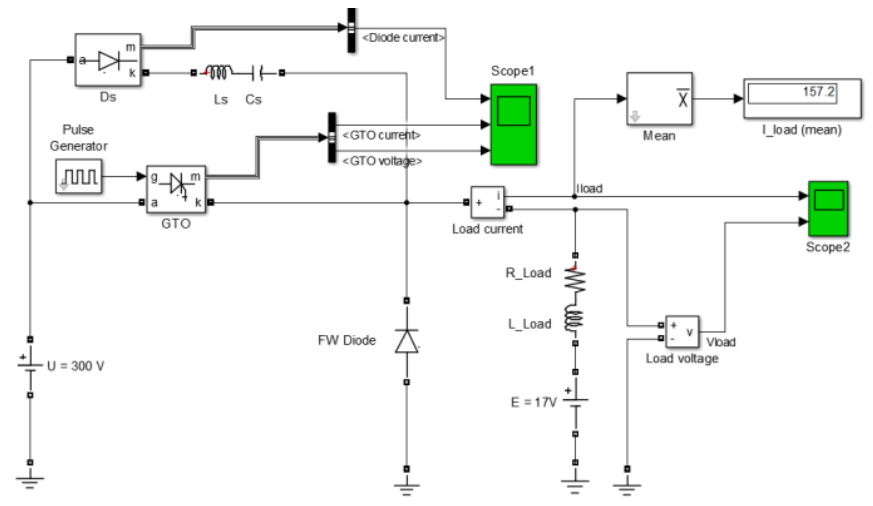

Gambar 9. Simulasi Boost Converter

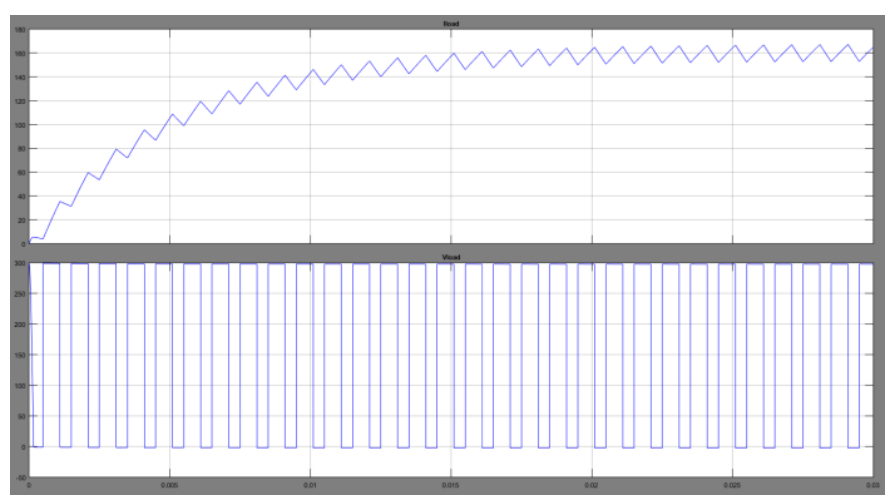

Gambar 10. Hasil Boost Converter

Berdasarkan Gambar 5.4 terlihat arus beban yang hasilkan oleh rangkaian boost converter dapat menghasilkan arus beban sebesar 160 Ampere dan Tegangan keluaran sebesar 300 Volt DC. Tegangan keluaran Boost Converter ini akan menjadi tegangan input Full-Bridge Inverter.

\section{B. Perancangan Full Bridge Inverter}

Simulasi perancangan Full-Bridge Inverter ditunjukkan pada Gambar 11, simulasi dilakukan dengan menggunakan IGBT. Masing-masing IGBT di trigger oleh sinyal PWM dengan frekuensi switching $1080 \mathrm{~Hz}$, indek modulasi sebesar 0.8 dan frekuensi AC adalah 60 $\mathrm{Hz}$.
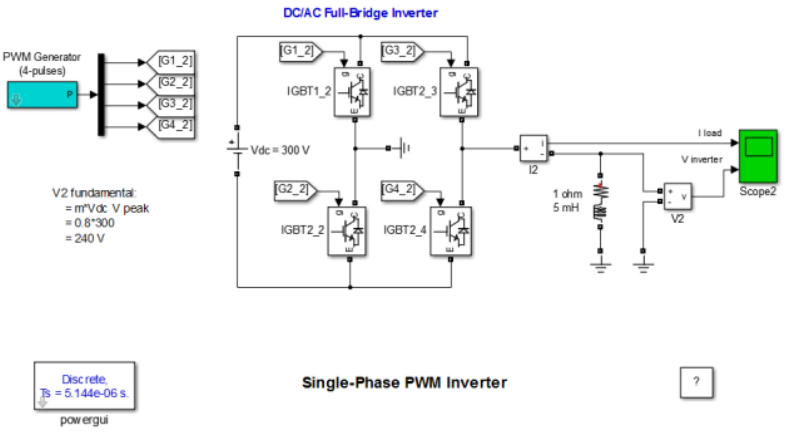

Single-Phase PWM Inverter

Gambar 11. Simulasi Full Bridge Inverter

Tegangan fundamental yang dihasilkan oleh inverter adalah besarnya indek modulasi dikalikan dengan tegangan puncak masukan dari inverter, yaitu 0.8 dikali 
300 VDC sama dengan 240 VAC. Hasil simulasi inverter ditunjukkan pada gambar 12, yaitu berupa arus pada beban dan tegangan full bridge inverter. Pada gambar terlihat arus beban sudah membentuk gelombang sinus, tetapi sinyal sinus yang dihasilkan masih mengandung ripple atau noise, hal ini disebabkan karena beban yang digunakan tidak hanya beban resistif tetapi juga beban induktif. Sedangkan, tegangan keluaran masih berupa pulsa gelombang persegi atau square wave. Hal ini terjadi karena inverter masih menghasilkan tegangan keluaran dengan banyak frekuensi, sehingga diperlukan filter untuk memperlihatkan tegangan keluaran dengan frekuensi yang dikehendaki.

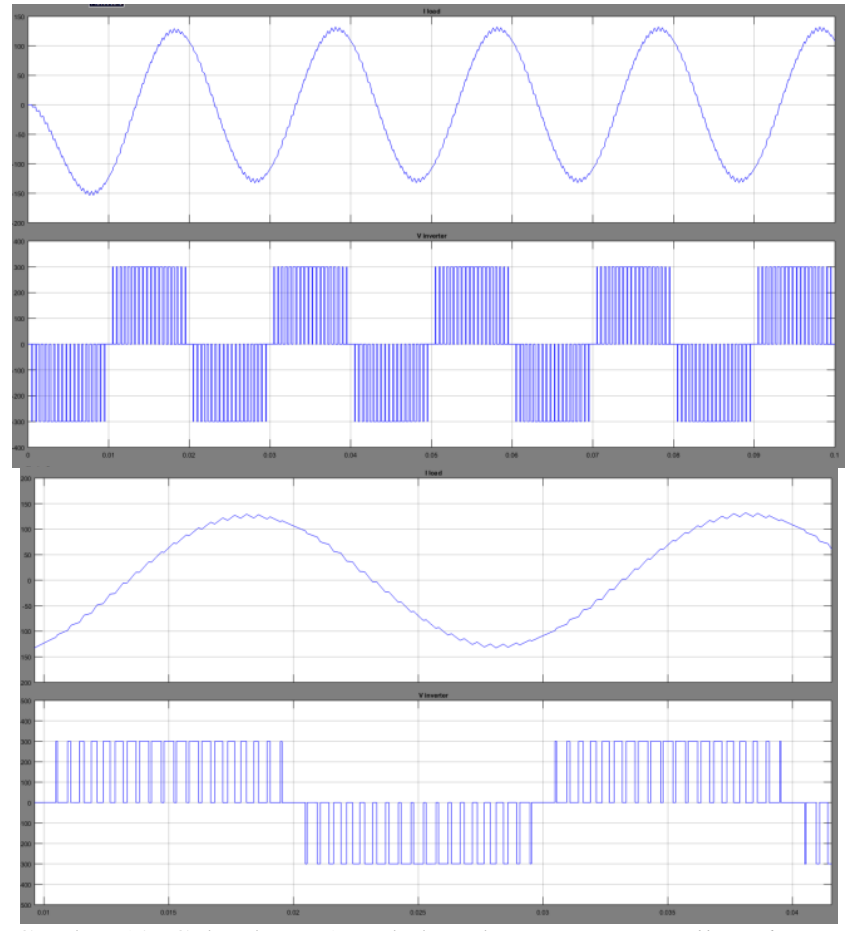

Gambar 12. Gelombang Arus beban dan Tegangan Full Bridge Inverter

Analisa tegangan keluaran inverter dilihat dari analisa THD (Total Harmonic Distortion) yang ditunjukkan pada gambar 13. Dari gambar tersebut terlihat terjadi distorsi atau kerusakan gelombang keluaran inverter dengan gelombang sinyal fundamentalnya sebesar 46,07\%. Hal ini berarti ripple yang terjadi sangat besar, sehingga diperlukan filter supaya menekan nilai ripple atau kerusakan sinyal gelombang output inverter.

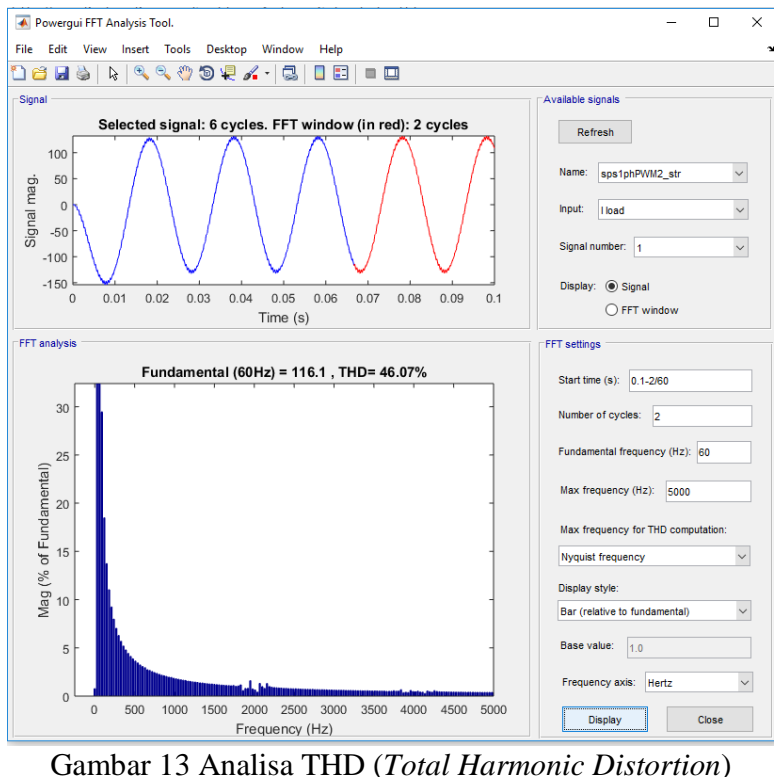

\section{Rangkaian Solar Power Inverter}

Spesifikasi panel surya yang gunakan adalah: Pmp $=249,86 \mathrm{~W}$

$$
\begin{aligned}
& \mathrm{Voc}=37,6 \mathrm{~V} \\
& \mathrm{Vmp}=31 \\
& \mathrm{Isc}=8,55 \mathrm{~A} \\
& \mathrm{Imp}=8,06 \mathrm{~A}
\end{aligned}
$$

Daya total yang bisa dibangkitkan mencapai 3498,04 Watt atau 3500 Watt pada kondisi irradiasi 1000 Watt $/ \mathrm{m} 2$ dan temperatur STC (Standart Temperature Condition) sebesar 25 derajat celcius, dengan jumlah panel SPV 14 unit dengan rangkaian 1 paralel dan 14 seri.

Rangkaian keseluruhan simulasi Solar Power Inverter ditunjukkan pada gambar 14.

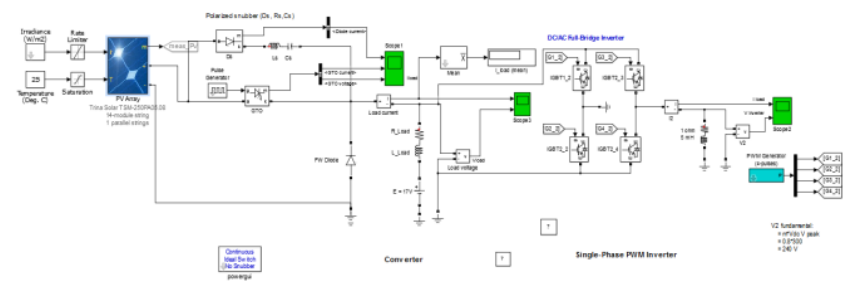

Gambar 14 Rangkaian keseluruhan Solar Power Inverter

\section{KeSIMPUlAN}

Dari penelitian yang telah dilakukan dapat diambil kesimpulan sebagai berikut:

1. Sistem Solar Power Inverter terdiri dari sistem Boost Converter dan Full Bridge Inverter.

2. Boost Converter dirancang dari tegangan $12 \mathrm{VDC}-$ 17 VDC menjadi tegangan 300 VDC

3. Full Bridge Inverter menghasilkan tegangan AC sebesar 240 VAC dengan indek modulasi 0.8 dan frekuensi $60 \mathrm{~Hz}$.

4. Total Harmonic Distortion sebesar $46.07 \%$

5. Daya panel Solar Photovoltaic yang dibangkitkan sebesar 3500 Watt pada kondisi irradiasi 1000 
Watt/m2 dan suhu temperature sebesar 25 derajat celcius.

\section{DAFTAR Pustaka}

[1] C.R Sanchez Reinoso, M.de Paula (2012). Photovoltaic Inverter Optimisation. 2nd International Conference on Advances in Energy Engineering,

[2] ABB, (2010). Technical Application Papers No 10: Photovoltaic Plants, No 116, ABB,

[3] Joachim Seel G.B., R. Wiser,(2010). Why Are Residential PV Prices in Germany So Much Lower Than in the United States? Environmental Energy

[4] Jain,Sachin,(2007). A Single stage grid connected inverter topology for solar PV system with maximum power point tracking, IEEE Transactions on power electronics, vol 22 no 5

[5] Dariusz Czarkowski, 2001, "DC-DC Converter in Power Electronic Handbook" Editing by Rashid,Muhammad H, University of Florida, chapter 13

[6] Ho, B.M.T., Chung, H.S-H,(2005). An Integrated Inverter With Maximum Power Point Tracking For Grid-Connected PV system. IEEE Trans Power Electron, pp..953-962, China.

[7] Jaysing, Kshirsagar,(2017). One cycle controlled single phase inverter for grid connected PV system, Advance in Electronic and Electric Engineering.

[8] .N.Prabaharan, A.Rini Ann Jerin (2017). Integration of Single Phase Reduced switch multilevel inverter topology for grid connected photovoltaic system. International conference on Alternative energy in developing countries and emerging economies. 